\title{
Anticorpos neutralizantes contra o vírus da Diarréia Viral Bovina (BVDV): comparação entre um imunógeno experimental atenuado e três vacinas comerciais inativadas ${ }^{1}$
}

\author{
Vaccination-induced neutralizing antibodies against bovine viral diarrhea virus (BVDV): comparison \\ between an experimental modified-live vaccine and three comercial inactivated vaccines
}

Marcelo de Lima ${ }^{2}$ Fernanda Silveira Flôres Vogel ${ }^{3}$ Eduardo Furtado Flores ${ }^{4}$ Rudi Weiblen $^{5}$

\section{- NOTA -}

\section{RESUMO}

Os títulos e duração de anticorpos neutralizantes contra o vírus da Diarréia Viral Bovina (BVDV) induzidos por uma vacina experimental atenuada (vacina A: dose única) foram comparados com os induzidos por três vacinas comerciais inativadas ( $B, C$ e D: duas doses com intervalo de 30 dias). Trinta dias após a vacinação (vacina $A$ ) ou após a segunda dose (vacinas $B, C$ e D), anticorpos neutralizantes contra o BVDV-1 foram detectados em todos os animais (12/12) do grupo A (título médio geométrico $G M T=1612,7)$; em 32 de 36 animais do grupo $B$ (GMT=14,3); 22 de 28 do grupo $C(G M T=25,1) ;$ e em 16 de 30 do grupo $D(G M T=40,0)$. Anticorpos frente ao $B V D V-2$ foram detectados em todos os animais do grupo A $(G M T=151,0)$; em 27 de 36 do grupo $B(G M T=10,0) ; 12$ de 28 do grupo $C$ $(G M T=11,5)$ e em 10 de 30 animais do grupo $D(G M T=10,0)$. No dia 180 após a vacinação, o número de animais que ainda apresentava anticorpos contra o BVDV-1 e os GMTs para cada grupo foram: vacina A $(12 / 12, G M T=905,0)$; vacina $B(30 / 36$, $G M T=28,3)$; vacina $C(20 / 28, G M T=28,3)$; vacina $D(14 / 30$, $G M T=16,1)$; e contra o BVDV-2 foram: vacina $A(12 / 12$, $G M T=56,6)$; vacina $B(18 / 36, G M T=16,8)$; vacina $C(10 / 28$, $G M T=21,6)$ e vacina $D(6 / 30, G M T=16,1)$. Os títulos médios (GMTs) induzidos pela vacina A foram significativamente superiores aos demais, tanto para o BVDV-1 $(P<0,0001)$ como para o $B V D V-2(P=0,01)$ nos diferentes períodos testados. Testes de soroneutralização cruzada demonstraram que os anticorpos induzidos pela vacina A reagiram em diluições maiores também com três isolados brasileiros de BVDV-1 e um isolado de BVDV2. Os resultados obtidos demonstram que a vacina experimental atenuada induziu títulos de anticorpos significativamente superiores, mais duradouros e com maior espectro de reatividade do que as vacinas comerciais. Esta vacina pode representar uma alternativa para o controle da infecção pelo BVDV no Brasil.

Palavras-chave: vírus da Diarréia Viral Bovina, BVDV, vacinas.

\section{ABSTRACT}

The titers and duration of neutralizing antibodies against bovine viral diarrhea virus (BVDV) induced by an experimental attenuated vaccine (vaccine A: one dose) were compared to those induced by three commercial inactivated ones ( $B, C$ and $D$ : two doses at a 30 day interval). Thirty days after vaccination (vaccine $A$ ) or the second dose (vaccines $B, C$ and $D)$, neutralizing antibodies to $B V D V-1$ were detected in all calves (12/12) from group A (mean geometric titer $G M T=1612.7)$; in 32 out of 36 from group $B(G M T=14.3) ; 22 / 28$ from group $C$ $(G M T=25.1) ; 16 / 30$ from group $D(G M T=40.0)$. Antibodies reacting with $B V D V-2$ were detected in all animals from group $A$ $(G M T=151.0) ; 27 / 36$ from group $B(G M T=10.0) ; 12 / 28$ from group $C(G M T=11.5)$ and in 10 out of 30 animals of group $D$ $(G M T=10.0)$. At day 180 post-vaccination, the number of animals reacting to $B V D V-1$ and the GMTs were: vaccine $A(12 / 12$, $G M T=905.0)$; vaccine $B(30 / 36, G M T=28.3)$; vaccine $C(20 / 28$, $G M T=28.3)$; vaccine $D(14 / 30, G M T=16.1)$; and against $B V D V$ -

${ }^{1}$ Trabalho realizado com suporte financeiro do Conselho Nacional de Desenvolvimento Científico e Tecnológico (CNPq), Coordenação de Aperfeiçoamento de Pessoal de Nível Superior (CAPES) e Financiadora Científica e Tecnológica de Estudos e Projetos (FINEP). Programa de Excelência (Pronex) em Virologia Veterinária: 215/96.

${ }^{2}$ Médico Veterinário, MSc, doutorando em Medicina Veterinária, Universidade Federal de Santa Maria (UFSM).

${ }^{3}$ Médico Veterinário, MSc, Doutor, Professor Adjunto do Departamento de Medicina Veterinária Preventiva (DMVP) da UFSM.

${ }^{4}$ Médico Veterinário, MSc, PhD, Professor Adjunto do DMVP, Centro de Ciências Rurais (CCR), UFSM, 97105-900, Santa Maria, RS. Fone/fax: 55-220-8034. Bolsista do CNPq (520758/96-0). E-mail: flores@ccr.ufsm.br. Autor para correspondência.

${ }^{5}$ Médico Veterinário, MSc, PhD, Professor Titular do DMVP, CCR, UFSM. Bolsista do CNPq (520161/97-1). 
2: vaccine $A(12 / 12, G M T=56.6)$; vaccine $B(18 / 36, G M T=16.8)$; vaccine $C(10 / 28, G M T=21.6)$ and vaccine $D(6 / 30, G M T=16.1)$. The geometric mean titers (GMTs) induced by vaccine A were significantly higher than those induced by the other vaccines $(B V D V-1: P<0.0001)$ and $(B V D V-2: P=0.01)$ in all days of testing. Cross-neutralization tests revealed that the antibodies induced by vaccine A cross-reacted to higher titers also with three Brazilian BVDV-1 and one BVDV-2 isolates. These results demonstrate that the experimental attenuated vaccine induced neutralizing antibodies in higher titers, duration and spectrum of reactivity than those induced by commercial vaccines. This vaccine may represent a future alternative for the control of BVDV infection in Brazil.

Key words: bovine viral diarrhea virus, BVDV, vaccines.

A infecção pelo vírus da Diarréia Viral Bovina (bovine viral diarrhea virus, BVDV) é distribuída mundialmente e pela sua repercussão econômica é considerada a virose mais importante de bovinos, após a Febre Aftosa (BAKER, 1995). Além de doença respiratória, doença gastroentérica (Diarréia Viral Bovina, BVD), enfermidade hemorrágica e Doença das Mucosas (DM), o BVDV pode causar reabsorção embrionária, abortos, mumificação, malformações fetais e o nascimento de bezerros persistentemente infectados (PI). Os bezerros PI excretam o vírus continuamente em grandes quantidades e constituem-se na principal fonte de disseminação do vírus (BAKER, 1995).

O controle da infecção pelo BVDV baseiase na identificação e remoção dos animais PI do rebanho, além da vacinação de animais susceptíveis, para prevenir a forma clínica, as perdas reprodutivas e a produção de animais PI (VAN OIRSCHOT et al., 1999). Vacinas com o BVDV atenuado ou inativado têm sido utilizadas no controle da infecção na América do Norte e Europa. A grande variabilidade antigênica do vírus e a existência de dois grupos antigênicos distintos (BVDV-1 e BVDV-2) prejudicam a eficácia das vacinas (VAN OIRSCHOT et al., 1999; DUBOVI, 2004).

A infecção pelo BVDV está amplamente difundida no Brasil, e vírus dos dois genótipos (BVDV1 e BVDV-2) estão presentes no rebanho brasileiro. As únicas vacinas disponíveis no mercado brasileiro contêm cepas norteamericanas inativadas, cuja eficácia tem sido questionada devido as suas diferenças antigênicas com as amostras brasileiras do vírus (FLORES et al., 2002). O presente trabalho teve como objetivo comparar a resposta sorológica induzida por uma vacina experimental com vírus atenuado recentemente produzida com isolados brasileiros do BVDV-1 e BVDV-2 (LIMA et al., 2004) com as respostas induzidas por três vacinas comerciais inativadas.
Cento e dezesseis bovinos, com idade entre 10 e 24 meses, soronegativos para o BVDV, foram alocados em cinco grupos e imunizados com a vacina experimental A ( $n=12)$, vacina inativada $B(n=36), C$ $(n=28)$ ou $D(n=30)$. Um grupo $(E, n=10)$ foi utilizado como controle não vacinado. A vacina A contém duas amostras atenuadas: BVDV-1 e BVDV-2 (LIMA et al., 2004) e as demais são vacinas comerciais que contêm cepas inativadas do BVDV-1, além de antígenos de outros patógenos. As vacinas $\mathrm{B}$ e C contêm hidróxido de alumínio, como adjuvante, e a vacina D contém adjuvante oleoso. Os animais do grupo A foram imunizados uma única vez com $1 \mathrm{~mL}$ do sobrenadante de cultivo celular contendo as amostras IBSP-2 (10 $10^{7,3}$ doses infectantes para $50 \%$ dos cultivos, DICC $\left._{50}\right)$ e SV-253 $\left(10^{6,8}\right.$ DICC $\left._{50}\right)$ pela via intramuscular (IM). Os animais dos grupos B, C e D foram imunizados duas vezes (intervalo de 30 dias), com $5 \mathrm{ml}$ pela via IM. Cento e oitenta dias após a vacinação, os animais do grupo A e alguns animais do grupo B ( $\mathrm{n}=24), \mathrm{C}$ (26) e D (28) foram revacinados. Os animais foram testados sorologicamente nos dias 0, 30, 60, 180 e 210 (30 dias após a revacinação) pela técnica de soroneutralização (SN) (BOTTON et al., 1998), frente a uma cepa do BVDV-1 (IBSP-2 para o grupo A; cepa Singer para os grupos B, C e D) e do BVDV-2 (cepa SV-253). Para a avaliação da reatividade sorológica cruzada, amostras de soro coletadas no dia 60 foram testadas frente a três isolados brasileiros do BVDV-1 (UFSM-1, SV-126.1, SV126.8) e um isolado do BVDV-2 (SV-260), caracterizados anteriormente (BOTTON et al., 1998). As médias dos títulos de anticorpos foram expressas em títulos médios geométricos (GMT).

A análise estatística foi realizada utilizandose o programa estatístico SAS (2001). O delineamento experimental adotado foi blocos ao acaso. As médias geométricas dos títulos de anticorpos (GMT) no dia 30 pós-vacinação (pv) (vacina A) e no dia $60 \mathrm{pv}$ (vacinas B, C e D), além dos títulos detectados nos dias 180 (reforço) e 210 pv foram submetidas à analise de variância (ANOVA) e comparadas através do teste de Tukey em nível de significância de 5\%.

A evolução dos títulos médios (GMT) de anticorpos neutralizantes produzidos em resposta às diferentes vacinas estão apresentados na figura 1A (frente ao BVDV-1) e 1B (BVDV-2). No dia 30 após a vacinação (vacina $A$ ) e 30 dias após a segunda dose (vacinas B, C e D), anticorpos frente ao BVDV-1 foram detectados em todos os animais do grupo A (12/12, GMT=1612,7); em 32 de 36 animais do grupo B (GMT=14,3); 22 de 28 do grupo C (GMT=25,1); e em 16 de 30 do grupo D (GMT=40,0). Nesta data, 


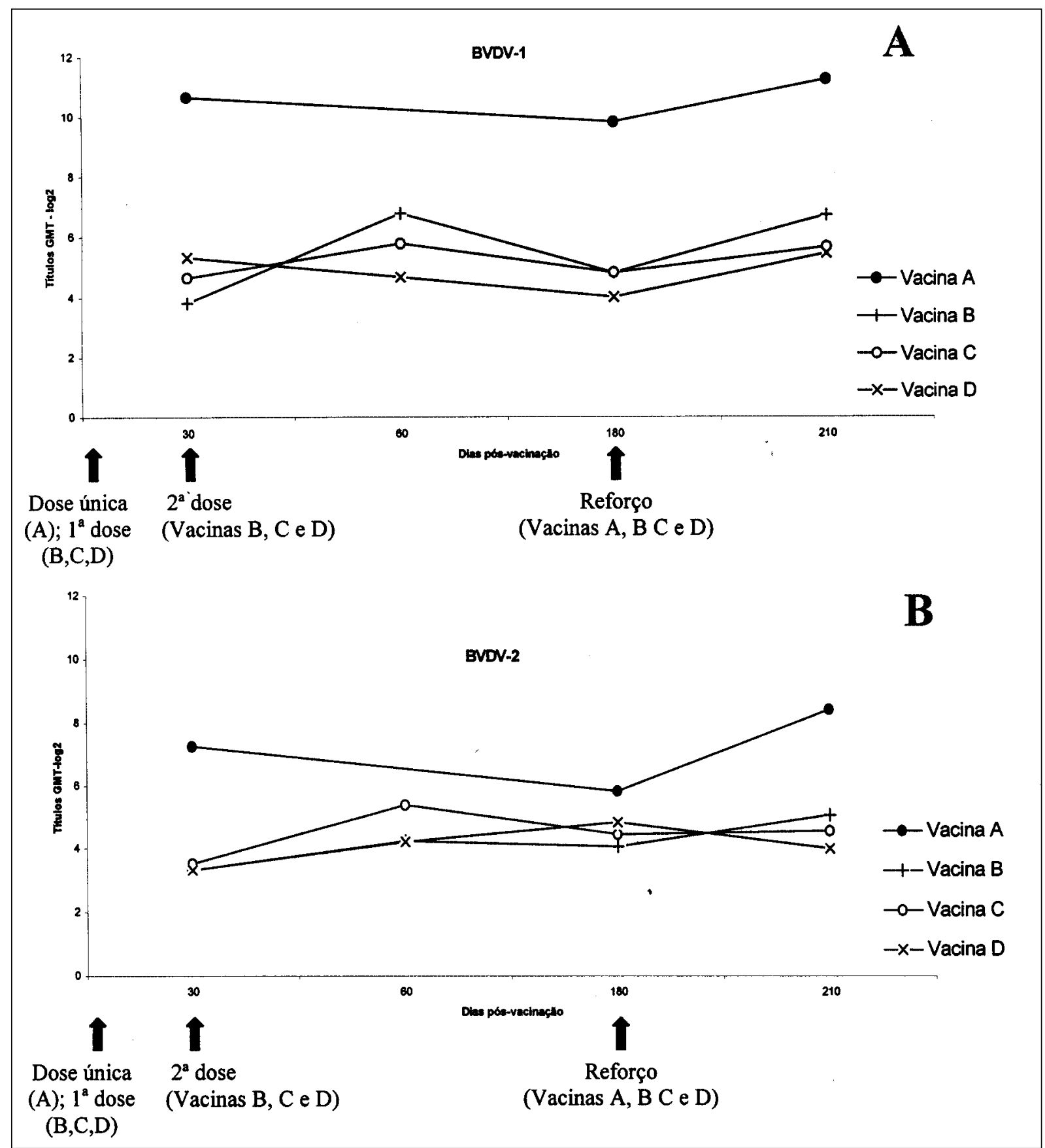

Figura 1 - Evolução dos títulos de anticorpos neutralizantes frente às amostras homólogas do BVDV-1 (A) e do BVDV-2 (B) no soro de bovinos imunizados com diferentes vacinas contra o vírus da Diarréia Viral Bovina (BVDV). Títulos expressos em média geométrica (GMT).

anticorpos frente ao BVDV-2 foram detectados em todos os animais do grupo A (GMT=151,0); em 27 de 36 do grupo B (GMT=10,0); 12 de 28 do grupo C $(\mathrm{GMT}=11,5)$ e em 10 de 30 animais do grupo D (GMT=10,0).

Cento e oitenta dias após a primeira dose, o número de animais que ainda apresentava anticorpos para o BVDV-1 era de $12 / 12$ na vacina $\mathrm{A}$ (GMT=905,0); 30/36 no grupo B (GMT=28,3); 20/ 28 no grupo $\mathrm{C}(\mathrm{GMT}=28,3)$ e $14 / 30$ no grupo $\mathrm{D}$ $(\mathrm{GMT}=16,1))$; e contra o BVDV-2: $12 / 12$ $(\mathrm{GMT}=56,6)$ na vacina $\mathrm{A}, 18 / 36(\mathrm{GMT}=16,8)$ na vacina $B, 10 / 28(G M T=21,6)$ na vacina $C$, e $6 / 30$ $(\mathrm{GMT}=16,1)$ na vacina $\mathrm{D}$. Trinta dias após o reforço 
(dia 210), observou-se um aumento nos títulos médios de anticorpos, principalmente frente ao BVDV-1 (títulos de 640 até 10.240; GMT=2.416,3), mas também frente ao BVDV-2 (títulos entre 160 e 1.280 , GMT=340,8). Os títulos neutralizantes induzidos pela vacina experimental foram significativamente superiores aos das vacinas inativadas (BVDV-1: $\mathrm{p}<0,0001$; BVDV-2: $\mathrm{p}=0,01$ ).

Os testes de sorologia cruzada frente a isolados brasileiros do BVDV-1 e 2 (Figura 2) detectaram títulos geralmente superiores frente ao BVDV-1 e novamente os títulos foram superiores nos animais imunizados com a vacina $\mathrm{A}$. Devido à grande variabilidade antigênica do BVDV, a capacidade do soro de animais imunizados de neutralizar isolados de campo antigenicamente diferentes constitui-se em um requisito fundamental para a eficácia de vacinas (VAN OIRSCHOT et al., 1999; DUBOVI, 2004). Nesse sentido, a baixa reatividade sorológica cruzada com amostras de campo brasileiras, especialmente do BVDV-2, tem sido apontada como uma das principais restrições às vacinas atualmente comercializadas no país (FLORES et al., 2002). Por isso, considera-se imperativa a inclusão de isolados dos dois genótipos (BVDV-1 e 2), e também dos subgenótipos BVDV-1a e 1 b nas vacinas (DUBOVI, 2004). Atualmente, alguns laboratórios nacionais estão desenvolvendo vacinas com cepas brasileiras de BVDV-1 e BVDV-2. Essas vacinas poderão representar um avanço no combate à infecção pelo BVDV no Brasil, pois certamente induzirão uma resposta sorológica de espectro mais amplo, capaz de neutralizar grande parte dos isolados de campo circulantes na população bovina do país.

Em resumo, o presente estudo demonstrou que a vacina experimental atenuada induziu títulos neutralizantes de magnitude superior e de maior duração do que as vacinas inativadas, corroborando observações anteriores que compararam estes tipos de vacinas (BOLIN, 1995; VAN OIRSCHOT et al., 1999). Vacinas atenuadas contra o BVDV não são atualmente licenciadas no país. No entanto, a sua inquestionável eficácia maior, aliada à necessidade de

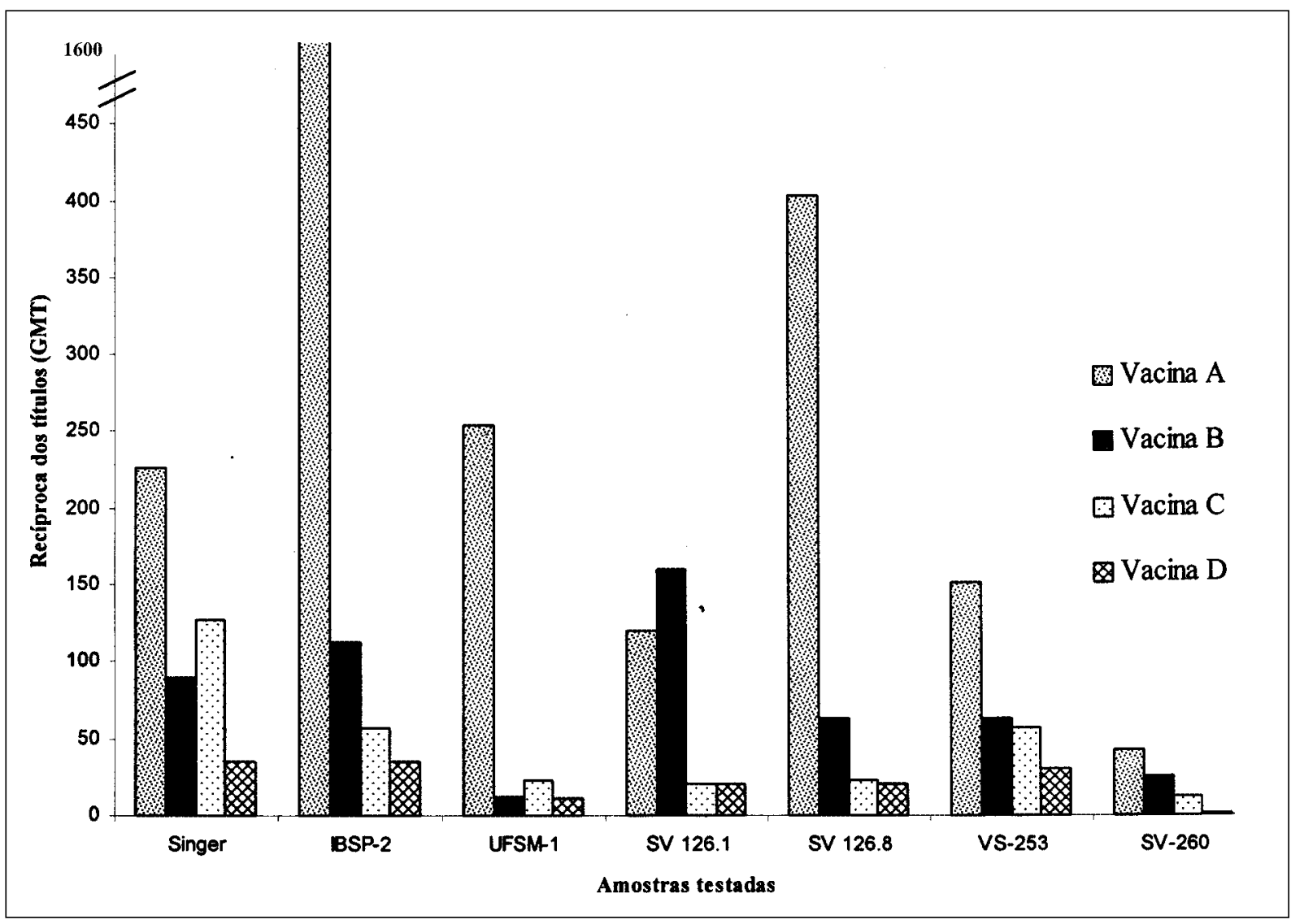

Figura 2 - Títulos de anticorpos neutralizantes no soro de bovinos imunizados com uma vacina experimental atenuada (A) e três vacinas comerciais inativadas (B, C e D) contra o vírus da Diarréia Viral Bovina (BVDV), frente a cepas de referência e isolados brasileiros do BVDV. Títulos expressos em média geométrica (GMT).

Ciência Rural, v.35, n.1, jan-fev, 2005. 
se reavaliar os critérios para o licenciamento de vacinas, assim como o precedente da liberação anterior de vacinas víricas atenuadas para outros vírus, abrem perspectivas de seu uso em um futuro próximo no Brasil. Nesse sentido, as cepas virais aqui testadas podem representar uma boa alternativa para a produção de vacinas atenuadas para o BVDV.

\section{REFERÊNCIAS BIBLIOGRÁFICAS}

BAKER, J.C. The clinical manifestations of bovine viral diarrhea infection. Vet Clin North Am, v.11, n.3, p.425-445, 1995.

BOLIN, S.R. Control of bovine viral diarrhea infection by use of vaccination. Vet Clin North Amer, v.11, n.3, p.615-625, 1995.

BOTTON, S.A. et al. Antigenic characterization of Brazilian bovine viral diarrhea virus isolates by monoclonal antibodies and cross-neutralization. Braz J Med Biol Res, v.31, n.11, p.14291438, 1998

DUBOVI, E.J. Vaccination programs for first calf heifers using combination of killed and modified live vaccines. In: BOVINE VIRAL DIARRHEA VIRUS IN THE AMERICAS SYMPOSIUM, 2004, Davis, CA. Proceedings... Davis : University of California, 2004. p84.

FLORES E.F. et al. Phylogenetic analysis of Brazilian bovine viral diarrhea virus type 2 (BVDV-2) isolates: evidence for a subgenotype within BVDV-2. Virus Res, v.87, p.51-60, 2002.

LIMA, M. et al. Caracterização de amostras atenuadas do vírus da Diarréia Viral Bovina (BVDV) tipos 1 e 2 para uso em vacinas. Pesq Vet Bras, v.24, n.1, p.35-42, 2004.

SAS. User's guide: statistics. Version. 8.02. Cary, NC : SAS Institute, 2001. 254p.

VAN OIRSCHOT, J.T. et al. Vaccination of cattle against bovine viral diarrhoea. Vet Microbiol, v.64, n.2/3, p.169-183, 1999. 